\title{
Poster-discussion: Asbestos
}

THE RISK OF ASBESTOS EXPOSURE IN SOUTH AFRICAN DIAMOND MINE WORKERS

Gill Nelson, Jill Murray, Jim Phillips National Institute for Occupational Health, Johannesburg, South Africa

10.1136/oemed-2011-100382.228

Objectives Asbestos is associated with South African diamond mines due to the nature of kimberlite and the location of the diamond mines in relation to asbestos deposits. Very little is known about the health risks in the diamond mining industry. The objective of this study was to explore the possibility of asbestos exposure during the process of diamond mining. Methods Scanning electron microscopy and energy dispersive X-ray spectroscopy analysis were used to identify asbestos fibres in the lungs of diamond mine workers who had an autopsy for compensation purposes, and in the tailings and soils from three South African diamond mines located close to asbestos deposits. The asbestos lung fibre burdens were calculated. We also documented asbestos-related disease in diamond mine workers at autopsy. 
Results Asbestos fibres were identified in the lungs of five men working on diamond mines. Asbestos was present in the mine tailings of all three mines. Asbestos-related disease was diagnosed in six diamond mine workers at autopsy.

Conclusions These findings indicate that diamond mine workers are at risk of asbestos exposure and, thus, of developing asbestos-related diseases. South Africa is a uniquely mineral-rich country and, when mining one commodity, it is likely that other minerals, including asbestos, will be accidentally mined. Even at low concentrations, asbestos has the potential to cause disease, and mining companies should be aware of the health risk of accidentally mining it. Recording of comprehensive work histories should be mandatory to enable the risk to be quantified in a future studies. 